\title{
Plasma Lipoproteins after Triglyceride Clearance in Cholesterol-fed Rats
}

Steven H. Quarfordt, Brian S. Oswald, Marwan O. Farouk, David C. Wehrenberg, Emma B. Morton, and Barry A. Landis

Departments of Medicine and Surgery, Durham Veterans Affairs and Duke University Medical Center, Durham, North Carolina 27710

\begin{abstract}
The clearance of particulate triglyceride from the plasma of cholesterol-fed rats with appreciable stores of hepatic cholesterol ester produces a substantial increment in plasma cholesterol. Most of this plasma cholesterol increment arises from existing tissue sources. The increment begins from 4 to $6 \mathrm{~h}$ after clearance and is due to the appearance of larger cholesterolrich, triglyceride-poor, $\beta$ migrating lipoproteins, which are isolated in the $d<1.063$ fraction with an apoprotein (Apo) content consisting primarily of Apo $E$ and smaller amounts of Apo B. A concurrent decrease in $\alpha$ lipoproteins occurs with the $\beta$ lipoprotein increment. Within $1 \mathrm{~d}$ of clearance the $\beta$ lipoproteins fall and $\alpha$ lipoproteins increase. The increase in total plasma Apo $E$ and Apo B initially parallels that of the cholesterol, but it persists even when cholesterol falls. A modest decrease in plasma Apo A1 was observed during the time $\alpha$ lipoproteins declined. A significant increase in plasma lecithin cholesterol acyl transferase preceded the increase in $\beta$ lipoprotein cholesterol. This enzyme increment was absent in rats with little lipoprotein response despite increased hepatic cholesterol. In vivo inhibition of this enzyme with dithionitrobenzoic acid virtually eliminated the postclearance hypercholesterolemia. Plasma particulate triglyceride clearance induces an increase in $\beta$ lipoproteins. Coupling of this clearance and hepatic lipoprotein secretion occurs by an unknown mechanism modulated by lecithin cholesterol acyl transferase. (J. Clin. Invest. 1993. 91:2532-2538.) Key words: cholesterol fed $\bullet \beta$ lipoprotein • lecithin cholesterol acyl transferase
\end{abstract}

\section{Introduction}

The presence of high plasma cholesterol concentrations in people from Western cultures, as compared with the much lower plasma cholesterol concentrations of the peoples of less developed societies, is attributed to the dietary differences of the cultures. The larger dietary cholesterol and lipid intakes of Western cultures are directly correlated with the plasma cholesterol concentrations (1). When the lipid intake of the diet is reduced, total cholesterol in both $\beta$ and $\alpha$ lipoproteins falls (2). The mechanism for this relationship is poorly understood at present.

A rat fed a standard laboratory diet supplemented with only cholesterol will produce hepatic cholesterol storage (3). When such a rat is then challenged with a bolus of chylomicrons or a synthetic triglyceride emulsion, it will produce an impressive increment in plasma cholesterol after a latent interval of up to 6

Address reprint requests to Dr. Steven Quarfordt, Research Building 2, 1st Floor, Veterans Affairs Medical Center, 508 Fulton Street, Durham, NC 27705.

Received for publication 22 April 1992 and in revised form 12 January 1993.

The Journal of Clinical Investigation, Inc.

Volume 91, June 1993, 2532-2538 $h$ (4). The increase in cholesterol-rich plasma lipoproteins is due to hepatic secretion (4) and will only occur when sufficient stored hepatic cholesterol is present and plasma particulate triglyceride clearance occurs (4). The data presented here characterize the sequential plasma lipoprotein changes observed after the plasma clearance of a synthetic triglyceride emulsion in such rats. They also indicate a function for the increase in plasma lecithin cholesterol acyl transferase (LCAT) ${ }^{1}$ during this clearance and in the subsequent rise of plasma $\beta$ lipoproteins.

\section{Methods}

Chemicals and radiochemicals. $\left[4-{ }^{14} \mathrm{C}\right]-$ and $\left[1,2-{ }^{3} \mathrm{H}\right]$ cholesterol were obtained from New England Nuclear Dupont (Boston, MA) and unlabeled cholesterol from Alltech Associates, Inc. (Deerfield, IL). Monospecific polyclonal antisera to rat apoprotein (Apo) B and Al were a generous gift of Dr. Paul Roheim (Louisiana State University, New Orleans, LA). Monospecific antisera to rat Apo $E$ were raised in the New Zealand rabbit. Heparin Sepharose, Sepharose 4B, and DEAE Sepharose were purchased from Pharmacia, Inc. (Piscataway, NJ). Dithio-bis-nitrobenzoic acid (DTNB) was obtained from ICN Biomedicals Inc. (Costa Mesa, CA). All solvents were reagent grade.

Animals and study protocols. Male Sprague-Dawley rats (250-450 g) were purchased from Charles River Breeding Laboratories (Raleigh, NC). They were maintained under usual light (6 a.m. -6 p.m.) and dark cycles and fed either standard laboratory diet or standard laboratory diet supplemented with $2 \%$ cholesterol (ICN Biochemicals, Cleveland, $\mathrm{OH}$ ) for up to $10 \mathrm{wk}$ before study. All rats were unrestrained and injections were made in the penile vein after light diethyl ether anesthesia. Blood was obtained from the tail veins. All injections were made the morning after a 10-h fast and blood was obtained before and at 1, 4, 8,12 , and $24 \mathrm{~h}$ after the injection. Some studies were prolonged or repeated on the second day as well, maintaining fasting. $20-30 \mathrm{mg}$ of Intralipid (Kabi Vitrum, Raleigh, NC) triglyceride, free of the excess phospholipid infranate (4), was injected to initiate each study. The injection of the LCAT inhibitor DTNB (10-15 $\mu \mathrm{mol})$ in $0.5 \mathrm{ml}, 0.12$ $\mathrm{M} \mathrm{NaCl}, 0.02 \mathrm{M} \mathrm{PO}_{4}$ (pH 7.6) (PBS) was given simultaneously with the triglyceride emulsion in the repeat study after the control response was assayed. Plasma was assayed for $\gamma$-glutamyl transpeptidase and alanine transaminase activities (5) 120 min after the DTNB.

Some rats were intravenously injected with either $10 \mu \mathrm{Ci}$ of [1,2$\left.{ }^{3} \mathrm{H}\right]$ - or $4 \mu \mathrm{Ci}$ of $\left[4-{ }^{14} \mathrm{C}\right]$ cholesterol on $1 \mathrm{mg}$ of $1: 1$ molar egg phosphatidylcholine/cholesterol $3 \mathrm{wk}$ before to study in order to achieve isotopic equilibrium.

Lipoprotein isolation. The centrifugal distribution of lipoproteins in cholesterol-fed rat plasma was determined at $d 1.006\left(1-10^{6}\right.$ $\times g \min ), 1.006-d 1.063$, and $1.063-1.21\left(2-10^{8} \times g \min \right)$ by a conventional method (6) using an ultracentrifuge (model L5-65, Beckman Instruments, Inc., Palo Alto, CA) with a Ti50 rotor at $15^{\circ} \mathrm{C}$. This distribution was evaluated in the baseline preinjection state and at various time intervals during the plasma cholesterol rise. The size distribution of the plasma lipoprotein cholesterol in baseline and stimulated states was evaluated by applying $2 \mathrm{ml}$ of the $\left[{ }^{3} \mathrm{H}\right]$ cholesterol plasma on a $1 \times 120-\mathrm{cm}$ Sepharose $4 \mathrm{~B}$ column and eluting with a $\mathrm{Na}_{2} \mathrm{HPO}_{4}(0.02 \mathrm{M}, \mathrm{pH} 7.6) \mathrm{NaCl}(0.12 \mathrm{M})$ buffer. Aliquots of the fractions were radioassayed in a liquid scintillation spectrometer

1. Abbreviations used in this paper: DTNB, dithio-bis-nitrobenzoic acid; LCAT, lecithin cholesterol acyl transferase. 
(model LS8100, Beckman Instruments, Inc.). The lipoprotein fractions isolated from the molecular sieve column were applied to a heparin affinity column by a method previously described (7). Plasma lipoprotein electrophoresis was done in $1 \%$ agarose gels with a barbital buffer using a commercial kit (Ciba Corning, Palo Alto, CA). The Oil Red O stain gels were scanned with a densitometer (model GS300, Hoefer Instruments, Inc., San Francisco, CA).

Lipid, apoprotein, and LCAT assay. Plasma lipoprotein total and free cholesterol were assayed using a cholesterol oxidase method as previously described (4). This method was also used to assay total and free cholesterol in a Dole ( 8 ) extract of plasma and homogenized liver. Phospholipid and triglyceride mass were also obtained by enzymatic assay using commercial kits (Wako Chemicals, Edgewood, NY). Protein mass was determined by the method of Lowry et al. (9). Apo B, E, and $\mathrm{Al}$ concentrations in rat plasma were determined using electroimmunoassay (10) employing monospecific antisera to each apoprotein. Apo $\mathrm{A} 1$ and $\mathrm{E}$ used for standards were isolated from rat lipoproteins by combined heparin Sepharose (7) DEAE and molecular sieve (11) chromatography. The pure proteins were characterized by SDS-PAGE (12). Apo B could not be isolated in a lipid-free state; therefore this apoprotein was expressed as a multiple of the preinjection value.

LCAT was measured in the plasma using $200 \mu \mathrm{g}$ of an 80:1 lecithin [4- ${ }^{14} \mathrm{C}$ ]cholesterol dispersion, $5 \mu \mathrm{l}$ of $\beta$-mercaptoethanol, and $15 \mu \mathrm{l}$ of sample in $0.25 \mathrm{ml}$ Tris buffer (13). This LCAT assay was incubated for $30 \mathrm{~min}$ at $37^{\circ} \mathrm{C}$. Upon completion of incubation, the lipid was extracted by the Dole method ( 8 ), applied to an activated silica gel TLC plate and developed in 80:20:1 petroleum ether, diethylether, acetic acid. $\left[4-{ }^{14} \mathrm{C}\right]$ cholesterol ester standards were also run on the plate and the ester samples scraped and radioassayed in 0.5\% 2,5-diphenyloxazole $0.1 \% p$-bis-[2-(5-phenyloxazolyl]-benzene in toluene and corrected for the standard recovery.

\section{Results}

The injection of the triglyceride emulsion produced a doubling of the cholesterol level in most cholesterol-fed rats (Fig. 1). The increase of the plasma cholesterol mass in these rats was accompanied by an identical increment of $\left[4-{ }^{14} \mathrm{C}\right]$ cholesterol in rats previously ( $3 \mathrm{wk}$ ) radiolabeled with the sterol to achieve isotopic equilibrium. During the time of the plasma cholesterol increment, the specific activity of the plasma cholesterol remained nearly identical (Fig. 1) to the specific activity found before this increase. A pronounced change in the electrophoretic distribution of the lipoproteins paralleled the cholesterol increment (Fig. 1). In most of the cholesterol-fed rats which had cleared plasma particulate triglyceride a change in the electrophoretic mobility of both $\alpha$ and $\beta$ lipoprotein was appreciated even before a significant increment in plasma cholesterol concentration. The migration of $\alpha$ lipoprotein increased and that of $\beta$ lipoproteins decreased at $4 \mathrm{~h}$ after clearance (Figs. 1 and 2). Peak appearance of the $\beta$ lipoprotein occurred at 8 and $12 \mathrm{~h}$, a time when the $\alpha$ lipoproteins were less apparent. Just as the increase in the plasma $\beta$ lipoprotein concentration was accompanied by a slower electrophoretic mobility of the lipoprotein, the mobility increased as its concentration fell. By $20 \mathrm{~h}$ there was a decrease in the $\beta$ lipoprotein concentration with an increase in the electrophoretic mobility of this lipoprotein. $\alpha$ lipoproteins began to reappear at this time. When the plasma lipoprotein change was followed for longer times (Fig. 2 ) a reversal in the relative concentration of $\beta$ and $\alpha$ lipoprotein was noted. At $50 \mathrm{~h}$, the $\beta$ lipoprotein concentration was considerably less than the $\alpha$ lipoprotein concentration. At this time the relative $\alpha$ lipoprotein concentrations had usually increased over preinjection values when evaluated by densitometry (percent Oil Red-stained $\alpha$ lipoprotein/total Oil Red O-stained lipoprotein, mean $\pm \operatorname{SE}[\mathrm{n}=4]: 38 \pm 6,31 \pm 8,14 \pm 7,12 \pm 8$, and $78 \pm 12$ at $0,4,8,12$, and $50 \mathrm{~h}$, respectively). A minimal decrease in plasma triglyceride occurred (Fig. 2 ) over the $50 \mathrm{~h}$ in these fasting rats.

The ultracentrifugal distribution of plasma cholesterol also changed during the postclearance increment (Fig. 3). These rats had a maximal cholesterol increment somewhat later than previously described (4). The largest increment occurred in the $d 1.006-1.063$ fraction. A smaller increase was observed in the $d<1.006$ fraction at $24 \mathrm{~h}$ with no indication of a precursorproduct relationship with the $d 1.006-1.063$ fraction. A decrease in the $d 1.063-1.21$ cholesterol was noted at the beginning of the plasma cholesterol increase but was not followed for a sufficient interval to define a significant increase over preinjection values as noted by electrophoresis. A significant difference in the lipoprotein size distribution after tracer cholesterol was observed in the comparison between preclearance and postclearance peak cholesterol plasmas (Fig. 4). A considerable increase in larger lipoprotein $\left[1,2-{ }^{3} \mathrm{H}\right]$ cholesterol with less of a change in smaller lipoprotein $\left[{ }^{3} \mathrm{H}\right]$ cholesterol was noted

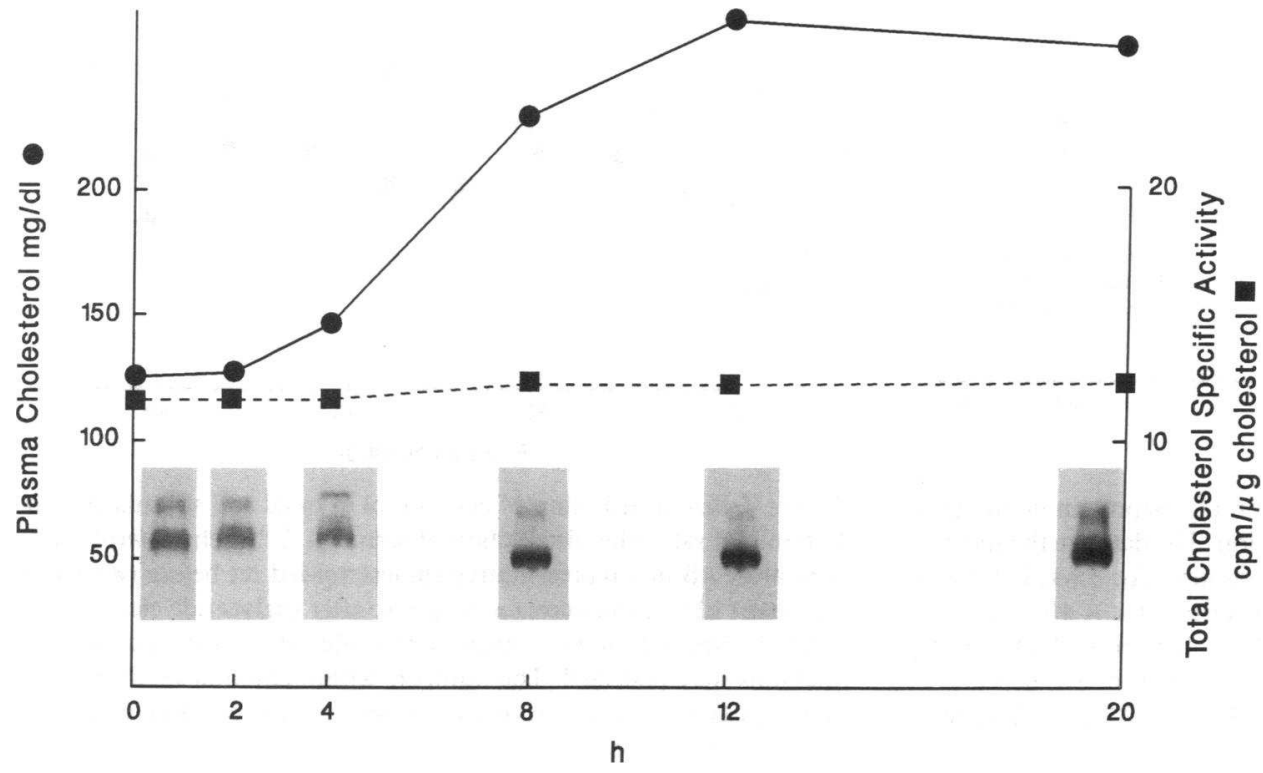

Figure 1. Early effect of plasma particulate triglyceride on plasma lipoprotein cholesterol. Changes in plasma cholesterol concentration $(\bullet)$, specific activity ( $\bullet$ ) and lipoprotein electrophoretic pattern (below specific activity) in a representative cholesterol-fed rat $(2 \% ; 6 \mathrm{wk})$ over the initial $20 \mathrm{~h}$ after the intravenous injection of $20 \mathrm{mg}$ of a triglyceride emulsion. The serum lipoprotein electrophoresis application site was the same for each of the six electrophoretic strips. 


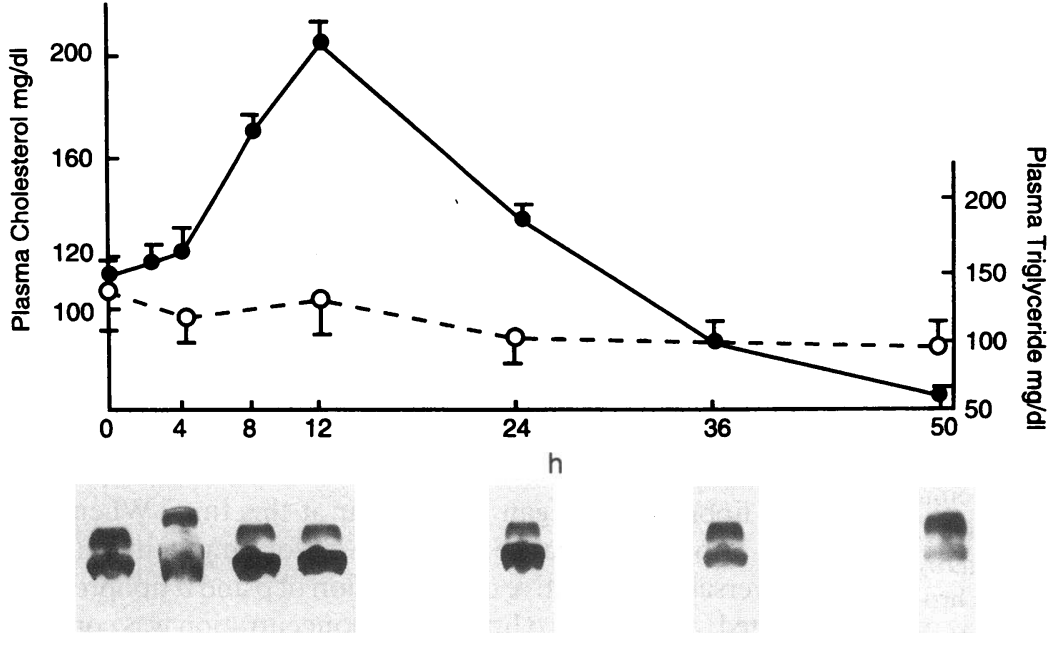

Figure 2. Later effects of plasma particulate triglyceride on plasma lipoproteins. Changes in plasma cholesterol concentration and lipoprotein electrophoretic pattern in cholesterol fed rats $(2 \% ; 3$ wk) injected with a triglyceride emulsion and evaluated for $50 \mathrm{~h}$. The cholesterol $(\bullet)$ and triglyceride $(0)$ data are the means \pm SE of four rats and the lipoprotein electrophoresis is from one representative rat. after clearance. The preclearance larger lipoproteins were predominantly heparin unbound $(78 \%)$, whereas the postclearance larger lipoproteins were mainly heparin bound $(74 \%$, Fig. 4).

The composition of the plasma lipoproteins in the preinjection or basal state differed from those in the postinjection maximum cholesterol or stimulated state (Table I). The basal VLDL contained more triglyceride than cholesterol whereas the opposite was true for stimulated VLDL. A reduction in percent triglyceride in stimulated LDL was noted when compared with the basal fraction. The relative phospholipid contents increased for the stimulated LDL and VLDL as compared to basal contents suggesting more surface area for these lipoproteins. The apoproteins of both basal and stimulated LDL and VLDL were predominantly Apo E and B and increased in content after clearance in proportion to the lipoprotein increment (Fig. 5). Relative amounts of Apo A1 in both stimulated and basal HDL were similar. A slight increment in the proportion of Apo E was seen in stimulated HDL (Fig. 5) in comparison with this lipoprotein before triglyceride clearance.

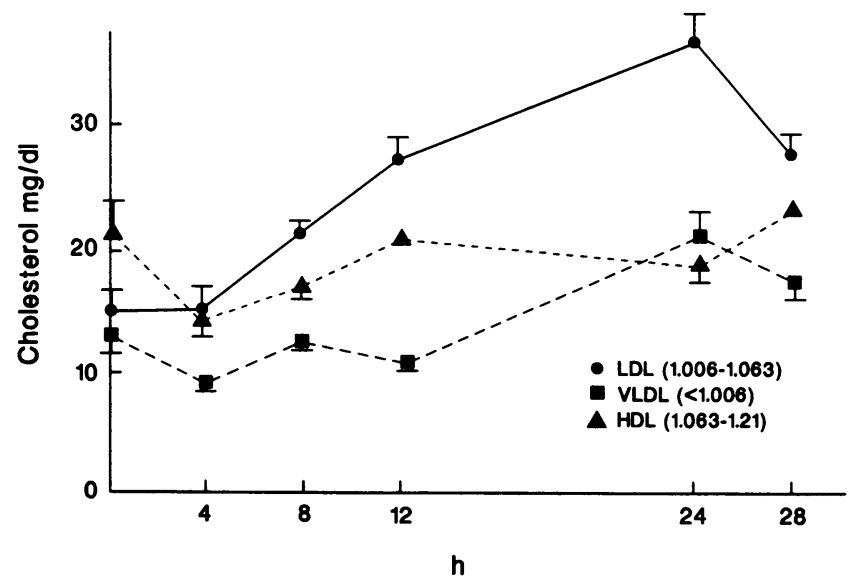

Figure 3. The ultracentrifugal distribution of lipoprotein cholesterol after the clearance of a triglyceride emulsion. The data are the means from four rats supplemented with $2 \%$ cholesterol for $3 \mathrm{wk}$. Ultracentrifugation was done at the indicated densities for $1 \times 10^{8} \mathrm{gmin}$ (VLDL); $1.5 \times 10^{8} \mathrm{gmin}$ (LDL); and $2.5 \times 10^{8} \mathrm{gmin}$ (HDL) as described in the text. Total plasma cholesterols were $62 \pm 8,60 \pm 11$, $74 \pm 12,88 \pm 13,111 \pm 10$, and $84 \pm 6$ at $0,4,8,12,24$, and $28 \mathrm{~h}$, respectively.
The increase in plasma cholesterol occurring 4-8 $\mathrm{h}$ after particulate triglyceride clearance (Fig. 6, middle panel) is associated with a similar increase in total plasma Apo E (Fig. 6, lower panel). A small decrease in plasma Apo E concentration virtually always preceded this increase even though in this study the relatively large standard error made it insignificant when compared to 1-h values. This occurred at the same time (2-4 h) at which both $\alpha$ and $\beta$ lipoproteins demonstrated altered electrophoretic mobilities (Figs. 1 and 2). A consistent finding in each cholesterol-fed rat was the continued increase of the Apo E concentrations at times ( $>12 \mathrm{~h}$ ) after plasma cholesterol concentrations decreased. This would result in the postclearance development of lipoproteins progressively richer in Apo E than lipid after the plasma cholesterol maximum. An increment in plasma LCAT activity occurred in these cholesterol-fed rats (Fig. 6, upper panel). This increase in LCAT activity occurred during triglyceride clearance and peaked just before the cholesterol maximum.

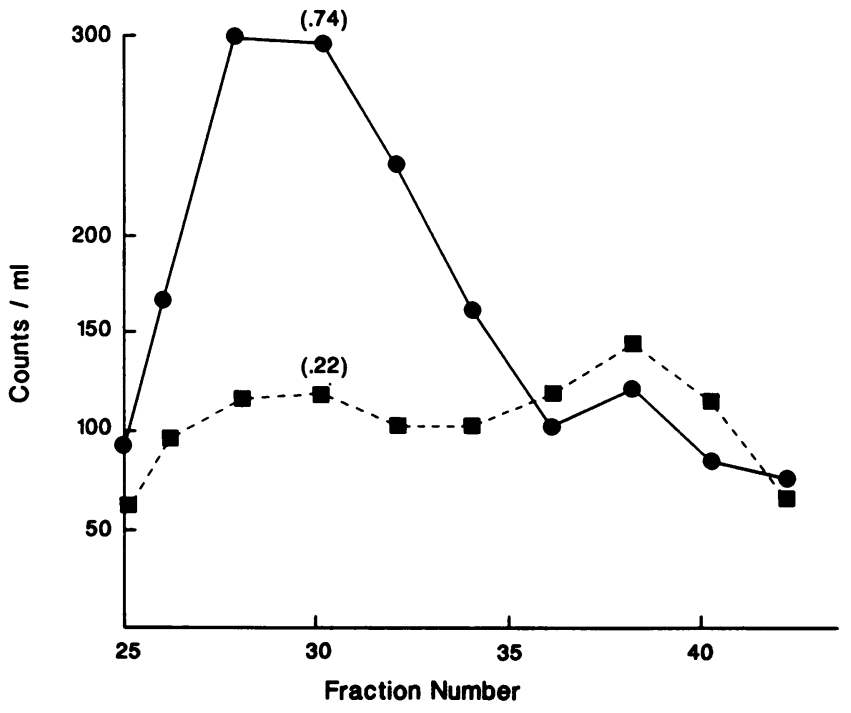

Figure 4. Size distribution of cholesterol in basal and stimulated cholesterol-fed rats. The distribution of serum $\left[1,2-{ }^{3} \mathrm{H}\right]$ cholesterol on Sepharose $4 B$ in a representative cholesterol-fed rat before $(\square)$ and at the peak $(12 \mathrm{~h})$ cholesterol $(\bullet)$ response after triglyceride clearance. $2 \mathrm{ml}$ of whole serum was applied to the column in each case and 2-ml fractions were collected. The numbers within parentheses over the initial peak is the fraction of $\left[{ }^{3} \mathrm{H}\right]$ lipoprotein in this peak that was bound to heparin-Sepharose. 
Table I. Composition of Basal and Stimulated Lipoproteins*

\begin{tabular}{|c|c|c|c|c|}
\hline & \multicolumn{3}{|c|}{ Total } & \multirow[b]{2}{*}{ Protein } \\
\hline & Triglyceride & $\begin{array}{l}\text { Total (free) } \\
\text { cholesterol }\end{array}$ & Phospholipid & \\
\hline & & $\%$ & & \\
\hline \multicolumn{5}{|c|}{$\begin{array}{l}\text { Very low density } \\
\qquad(d<1.006)\end{array}$} \\
\hline Basal & $52 \pm 5$ & $35 \pm 3(15 \pm 2)$ & $8 \pm 1$ & $6 \pm 1$ \\
\hline Stimulated & $32 \pm 2^{\S}$ & $47 \pm 3^{\prime \prime}(18 \pm 3)$ & $16 \pm 1^{\ddagger}$ & $6 \pm 1$ \\
\hline \multicolumn{5}{|c|}{$\begin{array}{l}\text { Low density } \\
\qquad(d 1.006-1.063)\end{array}$} \\
\hline Basal & $19 \pm 2$ & $51 \pm 2(19 \pm 4)$ & $20 \pm 1$ & $10 \pm 1$ \\
\hline Stimulated & $11 \pm 1^{\S}$ & $54 \pm 2(21 \pm 3)$ & $26 \pm 1^{\S}$ & $9 \pm 1$ \\
\hline \multicolumn{5}{|c|}{$\begin{array}{l}\text { High density } \\
\qquad(d 1.063-1.21)\end{array}$} \\
\hline Basal & $6 \pm 3$ & $38 \pm 4(14 \pm 7)$ & $29 \pm 4$ & $34 \pm 4$ \\
\hline Stimulated & $5 \pm 4$ & $40 \pm 3(17 \pm 6)$ & $26 \pm 7$ & $29 \pm 6$ \\
\hline
\end{tabular}

* The data represent the mean $\pm S E$ of five rats evaluated just before triglyceride injection (basal) and at the maximum of plasma cholesterol concentration (12 h) after the injection (stimulated). The lipoproteins were obtained at the densities indicated after ultracentrifugations of $1 \times 10^{8}$ gmin for very low and low density and $2 \times 10^{8}$ gmin for high density. Significantly different from respective basal at ${ }^{\ddagger} P<0.001,{ }^{\S} P<0.01$, " $P<0.05$.

The plasma concentration of Apo A 1 decreased after triglyceride clearance in these cholesterol fed rats (Fig. 7, upper panel). The minimum Apo Al concentration coincided with the maximum cholesterol concentration and occurred at similar times as the decrease in $\alpha$ (Fig. 1) and high density lipoproteins (Fig. 3). The concentration of Apo B increased progressively after clearance (Fig. 7, lower panel). In a manner similar to Apo E, the increase of Apo B continued even though plasma cholesterol had fallen resulting in particles with increased Apo $\mathrm{B} /$ cholesterol. When the plasma concentrations of both apolipoproteins were evaluated out to $48 \mathrm{~h}$ (data not shown), the Apo B returned to preclearance levels earlier than Apo E.

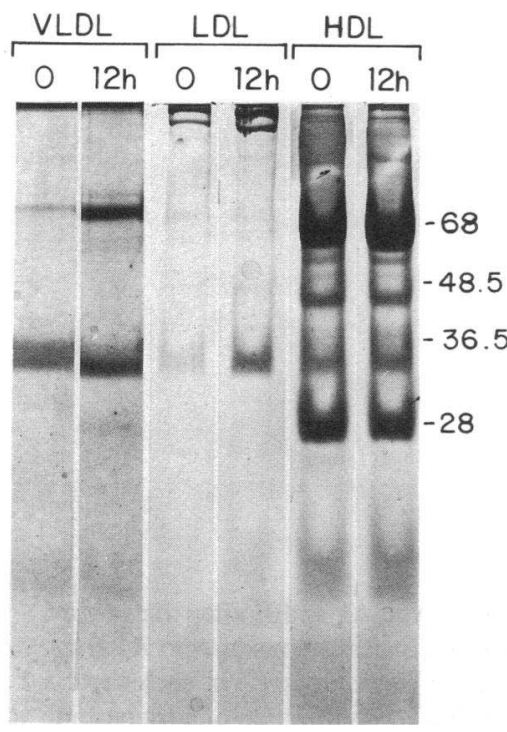

Figure 5. Basal and stimulated lipoprotein apoproteins. The apolipoproteins of very low, low, and high density lipoproteins before $(0)$ and during the maximal cholesterol increment $(12 \mathrm{~h})$ after triglyceride clearance evaluated on SDS 10\% PAGE. The HDL apoproteins are (from smallest to largest, bottom to top) Apo C, Apo Al, Apo E, Apo AIV, uncharacterized 62-74 kD apolipoproteins. The proteins loaded were derived from $0.4 \mathrm{ml}$ of plasma obtained from a four-rat pool and centrifuged as

described in the text with the exception of VLDL which was obtained from a $2-\mathrm{ml}$ plasma pool from the same four rats.
When cohorts of rats (consisting of three to eight rats per cohort) were fed a cholesterol-rich diet for a time sufficient to appreciably increase hepatic cholesterol, almost all of these groups ( 39 of 43 ) demonstrated the plasma cholesterol response described above for each rat in the group. The cohorts described in Figs. 2, 3, 5, 6, and 7 contained rats which were all responsive. Some groups had more sustained increments (Fig. 6) than others (Fig. 2) possibly a function of the duration of cholesterol feeding. An occasional group of rats demonstrated variability in response. Some responded to the triglyceride bolus with conventional $\beta$ lipoprotein cholesterol increment but others in the same group had little response despite having increased hepatic cholesterol (15-35 mg/g wet weight) contents. The active responders in such groups all showed appreciable increments in LCAT (Fig. 8). This was not the case for the poor responders who demonstrated little increase in plasma enzyme activity after the triglyceride bolus. When actively responding rats were injected with DTNB simultaneously with the triglyceride bolus, the cholesterol increment did not occur (Fig. 9). The clearance of the plasma particulate triglyceride was unaffected by the DTNB and no abnormalities of liver function tests (alanine transaminase, $\gamma$-glutamyl transpeptidase) were observed (data not shown).

\section{Discussion}

The plasma transport of particulate triglyceride in rats fed cholesterol for a period sufficient to appreciably increase hepatic cholesterol results in a consistent sequence of plasma lipoprotein shifts. Before the plasma triglyceride flux the concentrations of $\alpha$ and $\beta$ lipoprotein cholesterol may be similar or if the length of the preceding fast exceeds $16 \mathrm{~h}$, somewhat greater for $\alpha$ than for $\beta$. At $4 \mathrm{~h}$ after particulate triglyceride clearance an increase in $\beta$ lipoprotein becomes apparent though no appreciable change in total cholesterol mass occurs. This increase in $\beta$ lipoprotein begins at a time when the mobility of $\alpha$ lipoproteins, for unknown reasons, increase and the mobility of the $\beta$ lipoproteins decrease. During the following $8 \mathrm{~h}$, plasma cholesterol increases and $\beta$ lipoprotein becomes the dominant lipoprotein with a reciprocal decrease in $\alpha$ lipoproteins. In some cases, the $\alpha$ lipoproteins virtually disappear. This $\beta$ dominance persists for as long as $36 \mathrm{~h}$, at which time $\alpha$ lipoproteins increase while $\beta$ lipoproteins fall significantly. The reciprocal relationship between $\alpha$ and $\beta$ lipoprotein was clear when the lipoproteins were evaluated by electrophoresis or ultracentrifugation but was not as obvious when the lipoproteins were isolated by heparin-Mn precipitation (4).

These data clearly demonstrate the dependence of plasma lipoprotein distribution on the prandial state of the rat when the liver contains excess cholesterol. The periodic intake of dietary fat will intermittently provoke the hepatic secretion of $\beta$ lipoprotein cholesterol and make this lipoprotein the predominant plasma cholesterol transport form. A fasting state or the absence of dietary fat would lead to $\alpha$ or high density lipoproteins as the dominant plasma cholesterol transport form, similar to the standard laboratory diet-fed rat despite the presence of stored hepatic cholesterol. This considerable sensitivity of plasma lipoproteins to dietary fat is much less apparent (4) in standard laboratory diet-fed rats which have no increase in hepatic cholesterol. Reasons for the different responses to particulate triglyceride flux in livers containing excess cholesterol ester as opposed to those with little stored cholesterol are possi- 

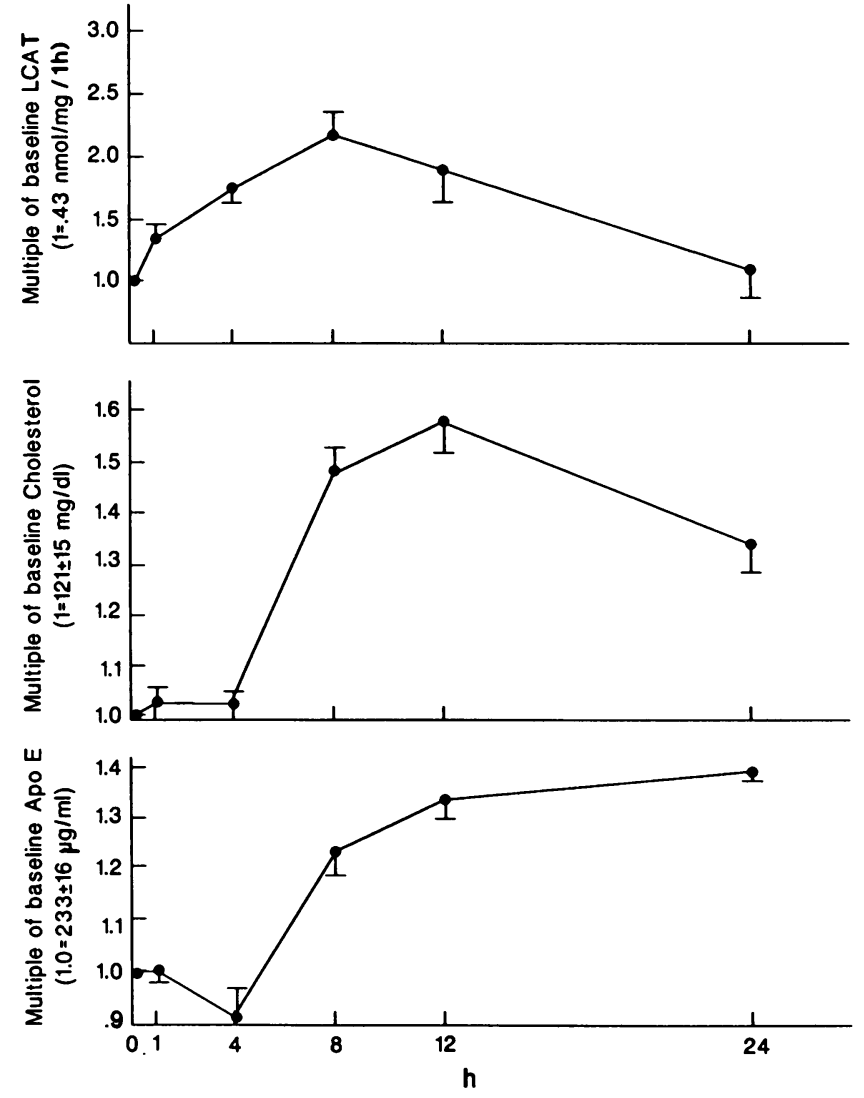

Figure 6. Plasma LCAT and Apo E after triglyceride clearance. The plasma cholesterol concentrations (middle panel), LCAT activities (top panel), and plasma Apo E concentrations (bottom panel) after the injection of a triglyceride emulsion in five rats fed cholesterol for $6 \mathrm{wk}$. Each of the data are the means \pm SE of five rats and were obtained simultaneously after the injection of $20 \mathrm{mg}$ of a triglyceride emulsion prepared as described in the text.

bly on the basis of the recognized (14) association of hepatic Apo B secretion with cholesterol ester formation.

The $\beta$ or low density lipoprotein has been suggested (15) to be the major transport form moving cholesterol from central hepatic stores to peripheral tissues. The appearance of $\beta$ lipo- protein after particulate triglyceride is not preceded by an obvious plasma precursor such as VLDL, although it is possible that a very rapidly turning over precursor could be missed. Previous studies (16) demonstrating the poor conversion of VLDL to LDL in rats are confirmed by these observations. The $\alpha$ or high density lipoproteins appear (17) to have a primary role in the net return of cholesterol from peripheral tissues to the liver. This $\alpha$ lipoprotein concentration increment occurring no sooner than $1 \mathrm{~d}$ after clearance is obviously not the result of the immediate transfer of surface phospholipid to this lipoprotein which occurs (18) during particulate triglyceride clearance. The data presented here indicate that the initial predominance of $\beta$ and subsequently the predominance of $\alpha$ lipoproteins represent a defined consistent sequence after particulate triglyceride clearance or enteral triglyceride exposure. Extrapolating these concentration changes to the functional roles of these lipoproteins would indicate that after the intestinal absorption and plasma processing of triglyceride in cholesterolfed rats, an interval ( up to $12 \mathrm{~h}$ ) of hepatic cholesterol export to peripheral tissue prevails. This is then followed by plasma lipoprotein conditions which would favor retrieval of peripheral tissue cholesterol with return to the liver.

This defined lipoprotein sequence and the dietary dependence of these events have important implications for cholesterol homeostasis. In the setting of excess hepatic cholesterol, the intake of dietary lipid with subsequent chylomicron formation produces mobilization and plasma transport of this hepatic cholesterol to peripheral tissues. This should down-regulate peripheral tissue synthesis and act to distribute the exogenous dietary cholesterol, stored primarily in the liver, to the periphery. Without the entry of this intestinal lipid the peripheral tissue in many of these cholesterol-fed rats would be largely exposed to alpha lipoproteins. These lipoproteins would not act to distribute the exogenous cholesterol stored in the liver as effectively as the $\beta$ lipoprotein and peripheral tissue cholesterol synthesis might be active despite the hepatic excess. This would create inputs of cholesterol from an exogenous source coinciding with unsuppressed peripheral tissue synthesis and would result in even greater inputs of cholesterol.

It is uncertain that the results found in the cholesterol-fed rat pertain to the human. Virtually all humans in the Western world ingest some cholesterol and their hepatic cholesterol
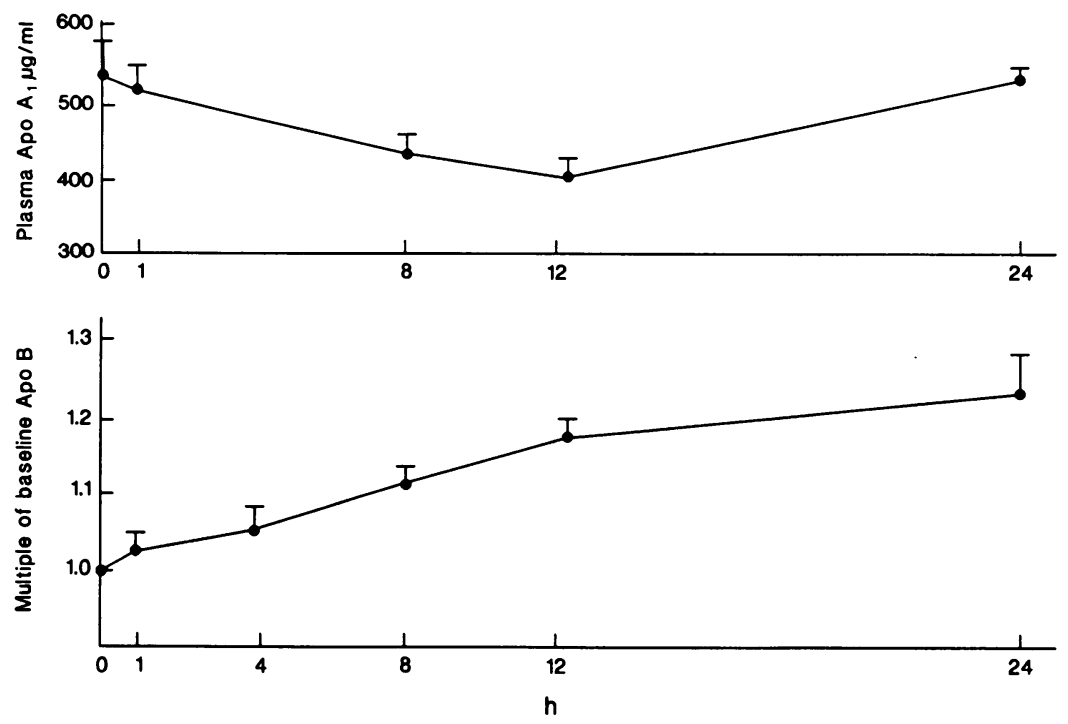

Figure 7. Plasma Apo Al and B after triglyceride clearance. Serum concentrations of Apo Al (top panel) and Apo B (bottom panel) in cholesterol-fed rats after the intravenous injection of a triglyceride emulsion. The data are from the same study that produced the data in Fig. 6 and represents the mean \pm SE of five rats. 


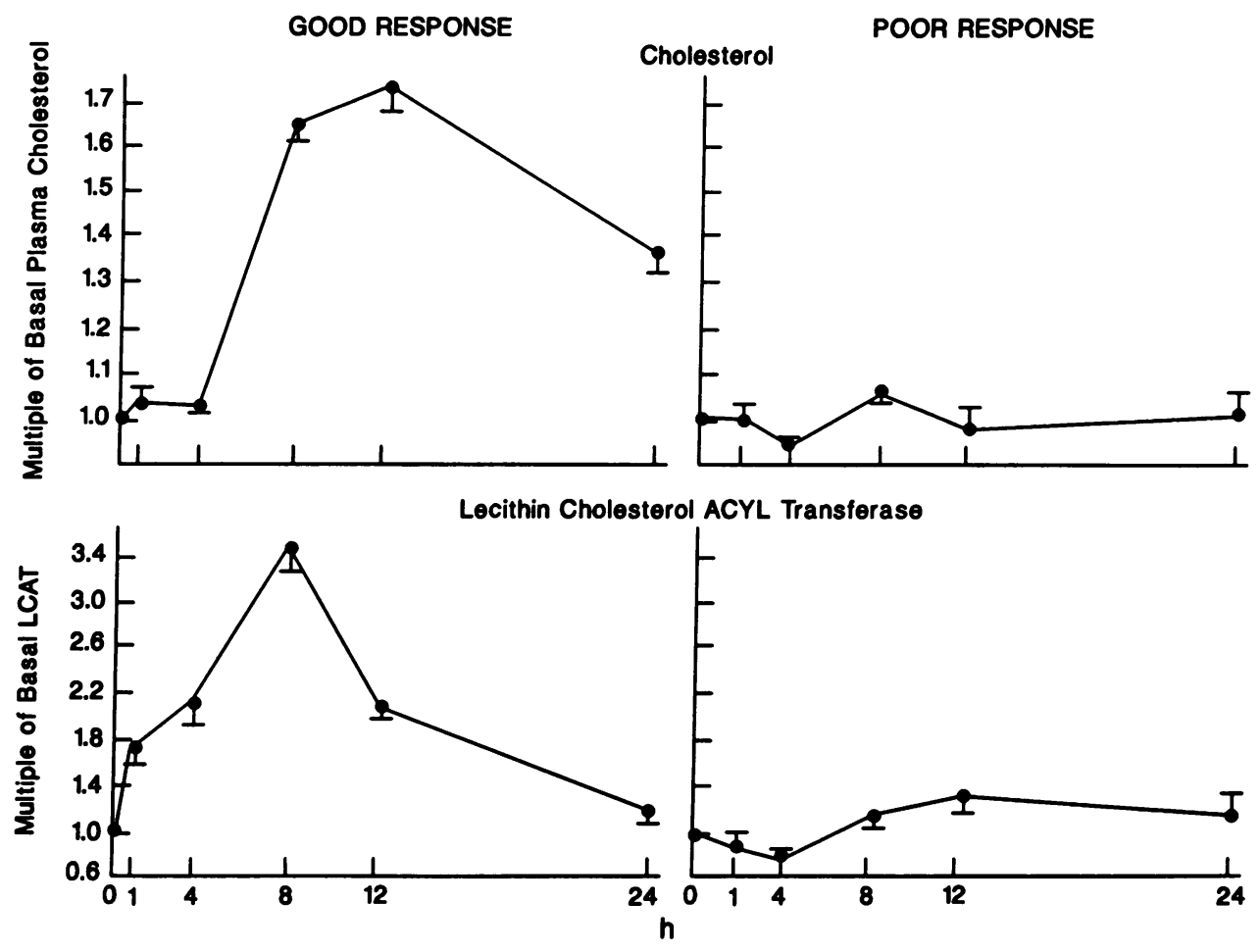

Figure 8. LCAT in cholesterol-fed rats with differing responses to triglyceride clearance. The plasma total cholesterol concentrations (top panels) and LCAT activities (bottom panels) after particulate triglyceride ( $20 \mathrm{mg}$ ) clearance in cholesterol-fed (6 wk) rats having an appreciable (good response; left panels) and a minimal (poor response; right pan$e l s$ ) increment in plasma cholesterol after the triglyceride. The data are the means \pm SE of four rats (good response) and three rats (poor response). contents would be anticipated to be greater because of this. The yet unexplained $(19,20)$ fall of plasma cholesterol in Western societies which maintain low fat or low calorie diets may occur on the basis of this mechanism. The lack of lipid ingestion would limit chylomicron transport below a level which would provoke hepatic cholesterol transfer to peripheral tissue as $\beta$ lipoproteins. This potential needs evaluation in appropriate clinical material.

The reciprocal relationship between the $\beta$ and $\alpha$ lipoproteins observed in most of the cholesterol-fed rats after triglyceride clearance was reflected in their major apoproteins. Apo E increased at the same time as the cholesterol and was one of the major apoproteins of the VLDL and LDL recovered at the maximum plasma cholesterol concentration. At this same time Apo Al decreased. The Apo $\mathrm{E}$ increment was equivalent to that of cholesterol during initial times. At later times the choles-

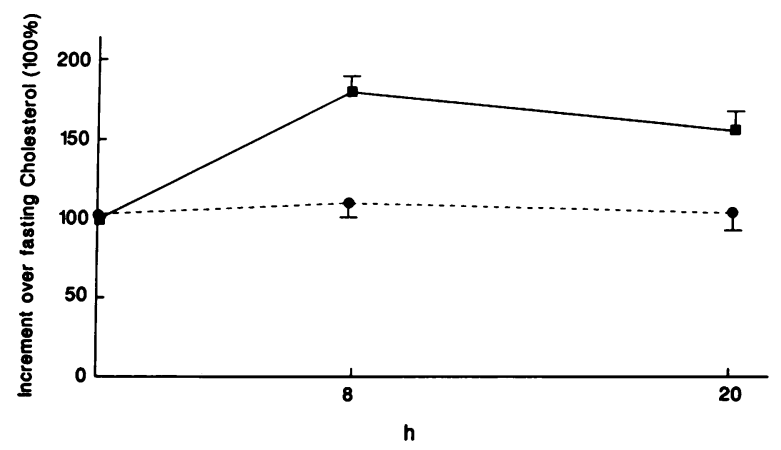

Figure 9. Plasma cholesterol response before and after DTNB. The relative plasma cholesterol concentrations in response to a triglyceride emulsion $(25 \mu \mathrm{g})$ in rats fed cholesterol for $4 \mathrm{wk}$ before $(\square)$ and after $(\bullet)$ the inhibition of LCAT with DTNB (10-15 $\mu \mathrm{mol}$ in $0.5 \mathrm{ml}$ of PBS) as described in the text. The data are the means \pm SE of the same four rats in the control (first day) and inhibited studies (following day). terol fell, along with the relative amount of $\beta$ lipoprotein lipid, yet the increment in Apo E continued. This was also true, though less pronounced, for Apo B which returned to baseline concentrations earlier than Apo E. The finding of a lipoprotein enriched in the apoproteins suggests either that the clearance process removes the cholesterol more rapidly than the apoprotein or an asynchrony of apoprotein-cholesterol hepatic secretion occurs, with smaller apoprotein rich lipoproteins secreted at later times. The clearance explanation can either be due to selective loss of the cholesterol from the particle or the more rapid removal of particles relatively enriched with cholesterol. The Apo B-rich LDL noted (21) in humans to be associated with greater atherosclerotic risk may occur through similar mechanisms.

The observation (22) that LCAT activity increases after oral lipid ingestion or an intravenous particulate triglyceride infusion has no explanation. The entry of lipid into plasma via intestinal chylomicrons is accompanied by a similar entry of Apo Al (18) on these particles. This apoprotein is a primary activator of the enzyme and potentially explains the postprandial increment. However, the plasma enzyme activity has also been documented (23) to increase after the plasma infusion of a triglyceride-rich emulsion which has little effect on Apo A1. In the present studies, plasma Apo Al is reduced at a time when LCAT activity increases. It is possible that the influx of the phospholipid-covered triglyceride particle provides a better substrate for the acylation or affords a more appropriate transport form for the product. It is also quite possible that new enzyme is released by the liver in response to the chylomicron flux although the increment in activity appears to precede remnant clearance.

The role of LCAT in the hepatic secretion of cholesterolrich lipoproteins initiated by particulate triglyceride is speculative. The enzyme metabolizes the phospholipid-free cholesterol surface of these particles producing cholesteryl esters 
(17). Although some of the ester remains with the triglyceriderich lipoproteins, much of it transfers (18) to high density or $\alpha$ lipoproteins, a lipoprotein which actually falls after clearance. The $\beta$ lipoprotein cholesterol increase occurs considerably later than that of the enzyme and continues beyond the maximum of the enzyme activity. This suggests that the increasing beta lipoprotein cholesterol is not an immediate product of the plasma enzyme or the remnant lipid. It is more likely that the enzyme has a role in initiating the hepatic stimulus which produces the secretion of the $\beta$ lipoproteins. The early fall in plasma Apo $\mathrm{E}$ concentration in cholesterol-fed rats, after plasma triglyceride clearance and before the rise in $\beta$ lipoprotein, suggests a role for the apoprotein in the subsequent secretion of $\beta$ lipoprotein cholesterol. Quite likely this invariable decrease in plasma Apo $\mathrm{E}$ after particulate triglyceride clearance reflects hepatic uptake of the apoprotein with the remnants. This may in turn provide a signal for hepatic $\beta$ lipoprotein secretion. Such a role is supported by observations that Apo E-supplemented triglyceride particles enhance cholesterol secretion from cholesterol-loaded hepatocytes in tissue culture and isolated perfusion (Quarfordt et al., manuscript submitted for publication). When the triglyceride particles were supplemented with cholesterol oleate their Apo E mediated uptake by hepatocyte monolayers was increased along with subsequent secretion of hepatocyte cholesterol (Quarfordt et al., manuscript in preparation ). The observation that DTNB aborted the plasma cholesterol increment may be due to its effect on LCAT although it may well have a prime influence on a yet unrecognized site. The finding of unusual rats that acquired hepatic cholesterol during feeding similar to their littermates yet had little cholesterol or LCAT response to particulate triglyceride supports an in vivo role for the enzyme in this process. Possibly the greater cholesterol secretion observed in cultured cholesterol rich hepatocytes noted for cholesterol ester rich as opposed to cholesterol ester poor triglyceride particles occurs in vivo as well and is the major role of LCAT in this process.

\section{References} 118.

1. Keys, A. 1952. Human atherosclerosis and the diet. Circulation. 5:115-

2. Jones, Y. D., J. T. Judd, P. R. Taylor, W. S. Campbell, and P. P. Nair. 1987. Influence of caloric contribution and saturation of dietary fat on plasma lipids in premenopausal women. Am. J. Clin. Nutr. 45:1451-1456.
3. Goodman, D. S. 1965. Cholesterol ester metabolism. Physiol. Rev. 45:747839.

4. Quarfordt, S. H., B. Oswald, B. Landis, E. DeFaria, and Y. Yamaguchi. 1991. Rat plasma cholesterol after particulate triacylglycerol clearance. Biochim. Biophys. Acta. 1082:247-250.

5. Young, D. S., L. C. Pestaner, and V. Gibberman. 1975. Effects of drugs on clinical chemistry tests. Clin. Chem. Special issue: 50 pp.

6. Havel, R., H. Eder, and J. Bragdon. 1955. The distribution and chemical composition of ultracentrifugally separated lipoproteins in human serum. $J$. Clin. Invest. 34:1345-1353.

7. Shelburne, F. A., and S. H. Quarfordt. 1977. The interaction of heparin with an apoprotein of human very low density lipoproteins. J. Clin. Invest. 60:944-950.

8. Dole, V. P. 1956. A relation between non-esterified fatty acids in plasma and the metabolism of glucose. J. Clin. Invest. 35:150-154.

9. Lowry, O. H., N. J. Rosebrough, A. L. Farr, and R. J. Randell. 1951. Protein measurement with the Folin phenol reagent. J. Biol. Chem. 193:265275.

10. Laurell, C. B. 1966. Quantitative estimation of proteins by electrophoresis in agarose gel containing antibodies. Anal. Biochem. 15:45-52.

11. Scanu, A., J. Toth, C. Edelstein, S. Koga, and E. Stiller. 1969. Fractionation of human serum high density lipoprotein in urea solutions: evidence for polypeptide heterogeneity. Biochemistry. 8:3309-3314.

12. Weber, K., and M. Osborne. 1969. The reliability of molecular weight determination of dodecyl sulfate-polyacrylamide gel electrophoresis. J. Biol. Chem. 244:4406-4412.

13. Albers, J. J., C. H. Chen, and A. G. Lacko. 1986. Isolation, characterization, and assay of lecithin-cholesterol acyltransferase. Methods Enzymol. 129:763-783.

14. Dashti, N. 1992. The effect of low density lipoproteins, cholesterol and 25-hydroxycholesterol on apolipoprotein B gene expression in Hep G2 cells. $J$. Biol. Chem. 267:7160-7169.

15. Brown, M. S., and J. L. Goldstein. 1980. Lipoprotein receptors in the liver. Control signals for plasma cholesterol traffic. J. Clin. Invest. 72:743-747.

16. Faergeman, O., T. Sata, J. P. Kane, and R. J. Havel. 1975. Metabolism of apoprotein B of plasma very low density lipoproteins in the rat. J. Clin. Invest. 56:1396-1403.

17. Glomset, J. A. 1968. The plasma lecithin:cholesterol acyltransferase reaction. J. Lipid. Res. 9:155-167.

18. Tall, A. R., P. H. Green, R. M. Glickman, and J. M. Riley. 1979. Metabolic fate of chylomicron phospholipids and apoproteins in the rat. J. Clin. Invest. 64:977-989.

19. Fox, J. C., H. C. McGill, Jr., K. D. Carey, and G. S. Getz. 1987. In vivo regulation of hepatic LDL receptor mRNA in the baboon. J. Biol. Chem. 262:7014-7020.

20. Spady, D. K., and J. M. Dietschy. 1985. Dietary saturated triacylglycerols suppress hepatic low density lipoprotein receptor activity in the hamster. Proc. Natl. Acad. Sci. USA. 82:4526-4530.

21. Sniderman, A., S. Shapiro, D. Marpole, B. Skinner, B. Teng, and P. O. Kwiterovich, Jr. 1980. Association of coronary atherosclerosis with hyper apobetalipoproteinemia [increased protein but normal cholesterol levels in human plasma low density (beta) lipoproteins]. Proc. Natl. Acad. Sci. USA. 77:604-608.

22. Marcel, Y. L., and C. Vezina. 1973. Lecithin:cholesterol acyltransferase of human plasma: role of chylomicrons, very low and high density lipoproteins in the reaction. J. Biol. Chem. 248:8254-8259.

23. Marcel, Y. L. 1982. Lecithin:cholesterol acyltransferase and intravascular cholesterol transport. Adv. Lipid Res. 19:85-136. 